\title{
Activity pattern of Asiatic black bear (Ursus thibetanus) in Machiara National Park, Azad Jammu and Kashmir, Pakistan
}

\section{Babar Zahoor}

Tsinghua University

Xuehua Liu ( $\nabla$ xuehua-hjx@mail.tsinghua.edu.cn )

Tsinghua University https://orcid.org/0000-0001-9717-0863

\section{Basharat Ahmad}

The University of Azad Jammu \& Kashmir

\section{Research Article}

Keywords: black bear, camera traps, food, hibernation, relative activity index, Zea mays

Posted Date: January 12th, 2022

DOI: https://doi.org/10.21203/rs.3.rs-1151381/v1

License: (c) (i) This work is licensed under a Creative Commons Attribution 4.0 International License.

Read Full License 


\section{Abstract}

The Asiatic black bear is considered an indicator species of the environment, hence, any change in the environment may alter its activity pattern. We monitored the monthly activity pattern of black bears in the moist temperate forests of Machiara National Park, AJ\&K, Pakistan. We used infrared camera traps and indigenous knowledge for data collection from April 2019 to April 2021. Camera traps recorded 109 (inside the forest $=107$, outside the forest $=2)$ independent registrations $(I R)$ within $5541(692.63 \pm 36.72$, mean \pm SD) camera days. We found that (i) spring and autumn were the lowest activity seasons of black bears inside the forest. (ii) Whereas, the highest activities were recorded in summer with peak activities in August followed by July $\left(X^{2}=203.5, d f=7, P<0.05\right)$. (iii) The activity level sharply declined after August and halted from late November to late April which was clear indication of bears' hibernation period. We collected indigenous knowledge from 70 selected persons, including hunters, herders, temporary residents and crop raiding victims. We used the data of human observation of latest three years and found that (i) bears remained active from May to November and hibernated rest of the period. (ii) The activities were at their peak inside the forest in summer (May - August) and out of the forest in autumn (September November) when it preferred to raid the widely cultivated maize crop (Zea mays) in the area. The capturing of black bears by camera traps outside the forest further supported the data provided by local people. Such switching over might have occurred due to the food preferences for Zea mays or easy access to abundant food availability out of the forest area. The current data can help mitigate human black bears conflict and consequently future conservation of black bears in the area.

\section{Introduction}

The Asiatic black bear is categorized as vulnerable under the IUCN red list of threatened species and considered as critically endangered species in Pakistan with population of 1000 individuals (Liu et al. 2009; Abbas et al. 2015; Zahoor et al. 2021a; Zahoor et al., 2021b). It is largely distributed in the forested landscape of northern Pakistan, including Khyber Pakhtun khwa, Gilgit Baltistan and Azad Jammu and Kashmir (Abbas et al. 2015; Ali et al. 2017; Zahoor et al. 2021c; Zahoor et al. 2021d). It prefers habitat with coniferous forest, oak and coniferous mixed forest, deciduous or broad leaf forest, shrubs and grasses (Liu et al. 2009; Trent, 2010; Zahoor et al. 2021d). Being an elusive and indicator species, it plays a vital role in the sustainability of an ecosystem (Sathyakumar et al. 2013). Black bears are omnivores but they mainly feed on fruits, thus help in seed dispersal which improves the forest quantity and quality (Steinmetz et al. 2013; Ali et al. 2017; Zahoor et al. 2021d).

Black bears are often involved in livestock depredation and crop raiding, therefore are usually killed in retaliation by the local people (Charoo et al. 2011; Jamtsho and Wangchuk 2016). The conflict starts from late spring that gradually intensifies at the end of autumn and attains its peak when maize (Zea mays) crop, one of its favorite food, is at ripening stage (Ali et al. 2017, Kazmi et al. 2019; Zahoor et al. 2021c; Zahoor et al. 2021d). People using maize grains as a staple food source and other vegetal parts as fodder for livestock (Zahoor et al., 2021c) come in conflict with black bear during crop raiding. 
Previous studies reported high intensities of human black bears conflicts in Pakistan (Ali et al. 2017; Kazmi et al. 2019; Waseem et al. 2020; Zahoor et al. 2021c; Zahoor et al. 2021d), however, there is no study available on activity pattern of black bears. In Taiwan, it was reported that in oak poor season, bears activity decreased and vice versa (Hwang and Garshelis 2007). Social stimulus, competition, predation, maternal behavior, and human disturbances (i.e., habitat degradation, hunting, and tourism) are also reported to affect the activity patterns in animals (Lewis and Rachlow 2011; Zhang et al. 2015; Leuchtenberger et al. 2018; Zahoor et al. 2021a). Detail studies of the key factors affecting activity pattern of a species can help develop comprehensive management plan for its better conservation.

Infrared camera traps and indigenous knowledge are often used to study the animals in the wild (Caravaggi et al. 2017; McPherson et al. 2016). Camera traps have extensively been used to study the activity pattern of the animals (Bu et al. 2016; Ikeda et al. 2016; Tang et al. 2017). Similar techniques were used to explore the activity pattern of black bears in the warm temperate forest and results were found satisfactory (Zahoor et al. 2021a).

Similarly, indigenous knowledge is the source of indirect information gathered from the people who usually interact with the wild animals, particularly in the areas like northern Pakistan, where human interferences are very high (Zahoor et al. 2021d). People often go to the forests for the collection of firewood, timber and medicinal plants and sometimes for hunting. Most of the people spend their summer months inside the forest areas where they involve themselves in different activities such as cultivation of crops and vegetables and grazing their livestock (Kabir et al. 2017; Zahoor et al. 2021c; Zahoor et al. 2021d). These people have good source of information about the wild animals due to their direct and indirect interaction with animals. Researchers often use such knowledge for distribution, abundance, demographics, trophic interactions, spatial ecology, and conservation status of wild animals and their threats (Camino et al. 2020). For the species like black bears the use of indigenous knowledge could be useful due to its conspicuous and cryptic nature (Zeller et al. 2011; Sathyakumar et al. 2013).

In present study, infrared camera traps were deployed and interviews were conducted to collect information on pre-designed questionnaires to explore the activity pattern of black bears in Machiara National Park (MNP), AJ\&K, Pakistan. We hypothesized that (i) black bears would be highly active in summer and autumn seasons. (ii) Hibernation period of black bears under moist temperate conditions should be longer than the bears living under subtropical and warm temperate conditions (Reid et al.1991; Zahoor et al. 2021a). The study aimed to find out (i) the monthly activity pattern and (ii) hibernation period of the Asiatic black bears under the moist temperate environmental conditions. The study would help to mitigate the human-black bears conflicts in and around the MNP and thus could be important for the management and conservation of black bears in the future.

\section{Materials And Methodology}

\section{Study area}


The study was conducted in the Machiara National Park located at 73.512879 E to 73.765536 E and 34.392427 N to $34.588498 \mathrm{~N}$, covering an area of 13,532 ha which was previously declared as game reserve and later on upgraded to the national park in 1996 (Fig. 1; Dar et al. 2009; Kabir et al. 2013; Zahoor et al. 2021d).

The mean annual temperature ranges from $14-27^{\circ} \mathrm{C}$ and mean annual rainfall is $1526.7 \mathrm{~mm}$, with an average 84.5 rainy days/year. July $(327.6 \mathrm{~mm})$ is considered as the wettest month, while November (Dar et al. 2009) as the driest month. Spring is the shortest season that lasts from March to April, while summer is the longest season and lasts from May to August. Autumn (September to November) and winter (December to February) both spread over 3 months each (Dar et al. 2009; Minhas et al. 2010). Summer is the warmest while winter is the coldest season when the study area remains covered with snow. There are 30 villages at the Southern fringe of the Machiara National Park, comprising 7,635 households with 52, 792 persons (Minhas et al. 2010; Minhas et al. 2012). The people mostly depend on the farming and livestock such as cattle, goats, sheep and buffalo for their livelihood. They usually use horses, mules, and donkeys for transportation of the heavy goods in the remote areas (Kabir et al. 2013). Northern areas of Pakistan including Machiara National Park is under high human interference, since people live temporarily inside the forest during summer months. They are usually involved in the activities such as deforestation, livestock grazing, hunting, and medicinal plants collection (Chattha et al.2012; Kabir et al.2017; Zahoor et al.2021c). The area is located within a Himalayan biodiversity hotspot and is a true representative of Mixed Forest-Rangeland Ecosystem. It possesses Himalayan moist temperate forests, Himalayan dry coniferous forests, subalpine scrub forest \& alpine pastures. The valuable flora such as Cedrus deodara, Picea smithiana, Abies pindrow, Prunus padus, Quercus incana, Quercus dilatata, Taxus wallichiana, Pinus wallichiana, Juglans regia, Aesculus indica, and Prunus cornutus are found in the area (Minhas et al. 2010a; Minhas et al. 2010b; Dar et al. 2012). The area is blessed with many globally threatened birds and mammals including snow leopard (Panthera uncia), common leopard (Panthera pardus), Hiamlayan musk deer (Moschus leucogaster), leopard cat (Prionailurus bengalensis), Asiatic black bear (Ursus thibetanus), Himalayan gray langur (Semnopithecus ajax), golden jackal (Canis aureus), and red fox (Vulpes vulpes) western horned tragopan (Tragopan melanocephalus), Monal Pheasent (Lophophorus impejanus) and koklas pheasents (Pucrasia macrolopha; Dar et al. 2009).

\section{Camera trap deployment}

Camera traps were deployed in consultation with wildlife department of Azad Jammu and Kashmir. We selected central area of MNP, with low risk of camera theft as human interference in this area was comparatively lower than that of other areas. We divided the area into $1 \mathrm{~km} \times 1 \mathrm{~km}$ grids and deployed one camera trap in each grid except two grids (where two camera traps were deployed on the right and left sides of a stream of each grid). We deployed total 18 cameras (15 Bestguarder SG-008 and 3 Ereagle E1) from the end of April 2019 to the end of April 2021. In the beginning, we deployed 10 cameras on 27th April 2019, followed by 5 cameras in early June and 3 more cameras in early August 2019. Camera traps were deployed inside the forest (along ridges) with tree trunks and under the rocks and covered with identical twigs and leaves to camouflage them properly against the risk of cameras theft. Due to 
minimum activity records in autumn 2019, one of the cameras was deployed out of the forest during autumn 2020, near crop fields at humans and livestock trails to check if there was any shift in the activity of black bears toward crop fields. Due to camera stealing issues, steep slopes and rugged terrain in the area, the heights of the cameras from ground were not uniform (Meek at al. 2014). The timing for capturing photos was set to capture 3 photos within 5 seconds with infrared flash. Monthly surveys were conducted to collect the data and replace the batteries even though cameras were still working with maximum battery charge.

\section{Interviews of local communities}

We selected communities adjacent to the forest zone, where we placed the camera traps for gathering information about black bears. We collected information from wildlife guards about the people who had ever seen black bears inside or outside the forest. We collected further information about black bears signs inside and outside the forests and its crop raiding pattern. To determine activity pattern of black bears, we used latest 3 years' data to minimize the chance of biasness. The data was primarily collected using questionnaires from temporary residents inside the forest area, herders, hunters, people who often visited the forest for vegetables, medicinal plants and fire wood collection, and victims of the crop raiding (Supplementary 1). We collected data from males only with age above 18 years and due to given social, ethnic and religious issues we could not interview women of the area.

\section{Data analysis}

We pooled the camera trap data of both years, and related the days and months collectively for the comparison and statistical analysis. Animal detections were grouped based on 30 min and if two animals were captured in the same photo, their independent registration was counted separately (Zhang et al. 2019; Zahoor et al. 2021a). Each capture was considered as an independent registration (IR). To determine monthly activity patterns, relative activity indices (RAl) was calculated as follows:

$$
\text { Monthlyactivitypattern }=\frac{\text { TotallRofthemonth }}{\text { Totalcameradaysofthemonth }} \times 100
$$

Whereas, the percentage of number of observations in each month was calculated based on bears seen in different months inside and outside the forest (in crop fields). The information about the monthly crop raiding of black bears was collected based on time period when it started raiding and when ended. To test the significant differences in monthly activity patterns and crop raiding pattern between different months, data was analyzed using Chi-square $\chi^{2}$-test (Zahoor et al. 2021c). All the statistical analyses were performed in R software version 3.6.1 (Adams 2013; Raijman and Shenkar 2016).

\section{Results}

\section{Camera traps output}


Out of all deployed cameras, 8 were stolen; 4 in June 2019, 1 in September 2019 and 3 in May 2020. We selected total 109 IR (including 2 IR near crop fields out the forest in September 2020) within 5541 (692.63 \pm 36.72 , mean \pm SD) camera days ( 2796 camera days of hibernation period were excluded, Fig. 2). We found August as the highest capturing month (RAl = 7.39), followed by July $(R A I=5.22)$ and October (RAI = 0.84).

\section{Indigenous data records}

We interviewed total 70 males who had observed black bears directly during last 10 years. To find monthly activity pattern of black bears, we included last three years' human observation (46 interviewees) data to minimize the biasness (Table 1). Maximum people (65.71\%) observed signs (e.g., pug marks fecal pellets, soil dug-out and debarking of trees) of black bears both inside and outside the forest. Some people $(25.71 \%)$ observed signs inside the forest and few ( $8.57 \%)$ outside the forest. All the interviewees reported high human interference in Machiara National Park due to livestock grazing and timber, firewood, vegetables and medicinal plants collection.

Table 1

Black bears evidences recorded by local people during last 3 years in Machiara National Park, AJ\&K, Pakistan

\begin{tabular}{|lccc|}
\hline Serial no. & No. of people & No. of observation & Total observations \\
\hline 1 & 29 & 1 & 29 \\
\hline 2 & 12 & 2 & 24 \\
\hline 3 & 4 & 3 & 12 \\
\hline 4 & 2 & 4 & 8 \\
\hline 5 & 1 & 5 & 5 \\
\hline Total & 48 & 15 & 78 \\
\hline
\end{tabular}

\section{Monthly activity pattern}

Camera trap results indicated that black bears showed a varied activity pattern (in terms of RAl) with highly significant difference between months (Chi-square test, $\chi^{2}=203.5, d f=7, P<0.05$ ). Activities started slightly from April to May and increased sharply after June and attained maximum peak in August. The activity level sharply decreased afterward with a slight increase in the October and decreased again afterwards. Therefore, the months of the late spring to mid-summer and autumn were considered as least activity months while no activity from late November to late April was a clear indication of bears' hibernation period (Fig. 3a).

Total 48 people (out of 70) observed the black bears 78 times inside and outside the forests of Machiara National Park. Black bears were seen from May to November with highly significant difference in the observations between months (Chi-square test, $\chi^{2}=58.07, \mathrm{df}=6, \mathrm{P}<0.05$ ). Most of the interviewees 
(35.90\%) observed black bears in the month of September, followed by August (29.49\%) and July $(14.10 \%)$ while there had been few reports of black bears in November and May (2.62\% in each month). No observation of black bears between December and April was an indication of its hibernation during these months (Fig. 3b).

\section{Intensity of black bears activity in autumn (based on IK)}

During autumn (September-November), most of the interviewees (88.72\%) observed black bears outside the forest in crop fields, while some of them (11.28\%) also reported to have seen black bears inside the forest. About $90 \%$ of the interviewees reported black bears out of the forest in September, October and November (Fig. 4).

\section{Crop raiding pattern of black bears}

Out of 70 interviewees 37 (53\%) were victims of the crop raiding by black bears, however, rests were also well aware of crop raiding issues in the area, thus, information (about crop raiding) were collected from all the interviewees. Collected data indicated that black bears started crop raiding from late August to early November. Crop raiding intensity during different months was highly significant $\left(\chi^{2}=47.38, d f=3\right.$, $P<0.05)$. Most of the people (51.43\%) reported crop raiding between September and October while very few (2.86\%) reported it from late August to early November (Fig. 5).

\section{Discussion}

\section{Monthly activity pattern of Asiatic black bears}

The Asiatic black bear is an umbrella species and plays an important role in the environmental stability (Yamamoto et al. 2012; Bashir et al. 2018). However, it often involves in the livestock depredation and crop raiding in summer and autumn seasons (Chauhan, 2003; Waseem et al. 2020; Yadav et al. 2009; Zahoor et al. 2021c). On the beginning of autumn season, when maize crop (Zea mays) starts to ripen, black bears movements increase out of the forest usually at night that leads to exponential increase in the rate of conflicts (Ali et al. 2017; Kazmi et al. 2019; Zahoor et al. 2021c).

The results of the camera traps indicated that black bears resumed their activity from late April that gradually increased with time. The activity halted after late November till late April that showed 4 to 5 months of hibernation period in the moist temperate forests of Machira Natioanal Park. The hibernation period was found consistent with the bears of moist temperate forests of western Himalaya (Sthyakumar et al. 2013; Waseem et al. 2020). Almost Similar pattern was observed by the local people i.e., temporary residents, herders, hunters, and victims of crop raiding. The peak activity timing of black bears inside the forest was usually pre-hibernation phase (i.e., summer and autumn) when surplus food is available in the form of fruits, green vegetation and nuts (Hashimoto 2002; Hwang and Garshelis 2007; Sathyakumar et al. 2013; Zahoor et al. 2021a). After it bears activity decline sharply and bears under sub-tropical to temperate environment start hibernation while their counterpart tropical bears do not hibernate (Reid et al. 
1991; Hwang and Garshelis 2007; Trent 2010; Zahoor et al. 2021a). However, camera results showed a sharp decline in the activity of black bears during autumn.

\section{Bear's autumn activities decline inside the forest}

We were assuming more or even similar activity level in the autumn as in summer as previous studies reported under tropical to temperate environmental conditions (Hwang and Garshelis, 2007; Zahoor et al. 2021a). However, we recorded almost negligible activities of black bears inside the forests. Based on indigenous knowledge and results of one camera trap (in autumn 2020) deployed out of the forest near crop fields indicates switching over of activities from inside to outside of forests. This decline may be attributed to the following reasons (i) the autumn food such as oak plants (Quercus spp.) is very important for black bears as acorn (fruit of Quercus spp.) is rich in fatty acids that helps in accumulating excess body fats in black bears before hibernation (Hwang and Garshelis 2007; Sunar et al. 2012; Akcan et al. 2017; Panthi et al. 2019). Previously, Zahoor et al. (2021d) reported the highest proportion of Quercus spp. in the black bears scats in the Machiara National Park. People living in these areas are also involved in harvesting oak wood, which is commonly used as fuel, timber, and agricultural tools such as handles of plough, axes, gun buts and walking sticks (Khan et al. 2011). Thus, insufficient Quercus spp. inside the forest is likely to make Asiatic black bears switch over its activities out of the forests in autumn. (ii) Maize crop is much nutritious, and milky in nature (Zahoor et al. 2021c) and its ripening in September attracts black bears to reside at the fringes of forest, from where they could raid nearby maize crop fields easily. Beside Quercus spp. Zahoor et al. (2021d) reported the 2nd highest proportion of Zea mays in the scats of black bears during autumn in Machiara National Park. The two IR (captured at night time) of black bears near crop fields in September and maximum observation by local people in autumn further confirms the bears activities out of the forest at the time of crop ripening (in autumn). In October, people start harvesting the Maize crop and arrange it in bundles in the crop fields. Bears activity declined after September, however there were some reports of black bear attacks on bundles of that crop. Cautious nature of the black bears, and their movement out of the natural habitat is often risky and usually cause the killings of the bears, perhaps, do not like to invade humanized area (Ashraf 2008; Jamtsho and Wangchuk 2016). But insufficient food availability inside the forests might be the reason for switching its intense activity from inside to outside of the forests. Based on one camera results (outside the forest), it can be concluded that black bears usually raid crops at night and stay in the nearby forest areas during day time. Temporary residents move down back to their native villages at the start of autumn, making black bears movement easy downwards in the valley in search of food. Previous studies (Hwang et al. 2010 and Sathyakumar et al. 2013) indicated that black bears traveled a long distance in search of food that means on finding food sources bears would like to stay near those sources. Thus, food availability or food preferences for the crops in nearby fields might have caused switching over of bears activities from inside to outside of the forest. The crop raiding continued throughout the autumn until people stored the crops after harvesting it.

\section{Proposed strategies for bears conservation}


Under such conditions we can predict more alarming situation in the future when food resources in the forests will further be depleted due to human population expansion, deforestation, agricultural practices, and climate change (Qasim et al. 2013; Songer et al. 2012; Panteriani et al. 2020; Zahoor et al. 2021d). This may increase the human black bears conflicts exponentially and rise in bears mortalities. Thus, government and wildlife departments of the AJ\&K need to take some early measures to curb these activities and conserve the habitats for forest dwelling species including black bears that mostly relies on plants. For instance, (i) temporary residents and timber mafia must be banned from entering the protected areas. (ii) Proper monitoring should be conducted to estimate the ratio between bears population and available food in different seasons. (iii) Make strategies to increase the range of protected areas for the conservation of forests and forest dwelling animals. Additionally, to overcome bears retaliatory killings, government should encourage the local people to fence their crop fields and use firecrackers to minimize the crop raiding issues. Like other countries (such as China) compensation scheme should be launched to compensate the losses /damages caused by bears (Dai et al. 2019).

\section{Limitations of the study}

The cameras were not deployed throughout the Machiara National Park due to highest rate of human activities in rest of the area. Given the high risk of camera theft, we deployed only one camera outside the forest area to monitor and compare the black bears activates. Even then 8 cameras deployed in comparatively low risk areas inside the forest were stolen during this study. We could not record the activities of black bears near crop fields in October and November due to insufficient deployment of camera traps. We could not collect the indigenous knowledge based data throughout the Machiara National Park, instead we were limited to collect the information from selected people residing in the vicinity of camera deployment sites. However, this study can play an important role to formulate the strategies for mitigating the human-black bears conflict in the area.

\section{Conclusion And Suggestions}

Black bears started activities from late April to late November in the Machiara National park that came to halt from late November to Late April (during hibernation). Results of camera traps recorded maximum activities of black bears in the summer while indigenous knowledge revealed maximum activities in the autumn. Indigenous knowledge and results of one camera (paced near crop fields) revealed that increased black bears activities out of the forest in the autumn was due to crop raiding. It might be due to the food preferences for Zea mays or easy access to abundant food availability that forced the bears to leave the forest area. We suggest to deploy more camera traps inside and outside the forests on bears dens and tracks near the crop fields to monitor the black bears activity in detail. We further suggest to launch community awareness programs prior to deployment of camera traps, particularly in the areas where human interference is very high. We believe that such steps will help explore the fluctuations of bears activities inside and outside of the forests of Machiara National Park where conflict rate usually increases before hibernation (in autumn).

\section{Declarations}


Acknowledgments

We express our great thanks to two NSFC (Natural Science Foundation of China) projects (No. 41671183 and No. 41271194) for providing the infrared camera traps. We thank Rufford Small Grant for financial assistance, Mr. Naeem Iftikhar Dar, Director of the Department of Wildlife and Fisheries of Azad Jammu and Kashmir, and wildlife staff for their support during the field study in the Machiara National Park.

\section{Declaration of interests}

The authors declare that they have no known competing financial interests or personal relationships that could have appeared to influence the work reported in this paper.

\section{Author contributions}

Paper concept: B.Z. and X.L.; Primary authorship: B.Z.; Additional review and editing: X.L. and B.A.; All authors have read and agreed to publish the final version.

\section{Ethical approval}

Not applicable.

\section{Consent to participate}

Not applicable.

\section{Consent to publish}

All the authors have declared their consent to publish the manuscript.

\section{Funding}

This research was supported by two NSFC (Natural Science Foundation of China) projects (No. 41671183 and No. 41271194) and Rufford small grant (project no. 27847-1).

\section{Availability of data and material}

The datasets used and/or analyzed during the current study are available from the corresponding author on reasonable request.

\section{References}

1. Abbas FI, Bhatti ZI, Haider J, Mian A (2015) Bears in Pakistan: distribution, population biology and human conflicts. J bioresour manag 2(2):1-13

2. Adams AM (2013) Assessing and analyzing bat activity with acoustic monitoring: challenges and interpretations, pp 1-176 
3. Akcan T, Gökçe R, Asensio M, Estévez M, Morcuende D (2017) Acorn (Quercus spp.) as a novel source of oleic acid and tocopherols for livestock and humans: discrimination of selected species from Mediterranean forest. J Food Sci Technol 54(10):3050-3057

4. Ali A, Waseem M, Teng M, Ali S, Ishaq M, Haseeb A, Aryal A, Zhou Z (2017) Human-Asiatic black bear (Ursus thibetanus) interactions in the Kaghan Valley, Pakistan. Ethology Ecol Evol 30(5):399415. https://doi.org/10.1080/03949370.2017.1423113

5. Bashir T, Bhattacharya T, Poudyal K, Qureshi Q, Sathyakumar S (2018) Understanding patterns of distribution and space-use by Ursus thibetanus in Khangchendzonga, India: Initiative towards conservation. Mamm Biol 92(1):11-20

6. Bu H, Wang F, McShea WJ, Lu Z, Wang D, Li S (2016) Spatial cooccurrence and activity patterns of mesocarnivores in the temperate forests of southwest China. PLoS ONE 11(10):1-15

7. Camino M, Thompson J, Andrade L, Cortez S, Matteucci SD, Altrichter M (2020) Using local ecological knowledge to improve large terrestrial mammal surveys, build local capacity and increase conservation opportunities.Biol Conservpp108450

8. Caravaggi A, Banks PB, Burton CA, Finlay CMV, Haswell PM, Hayward MW, Rowcliffe MJ, Wood MD (2017) A review of camera trapping for conservation behaviour research. Remote Sens Ecol Conserv 3:109-122

9. Charoo SA, Sharma LK, Sathyakumar S (2011) Asiatic black bear-human interactions around Dachigam National Park, Kashmir, India. Ursus 22:106-113

10. Chattha SA, lqbal S, Rasheed Z, Razzaq A, Husain M, Abbas MN (2013) Human-leopard conflict in Machiara National Park (MNP), Azad Jammu and Kashmir (AJ\&K), Pakistan. Pak J Zool 47(1):222228

11. Chauhan NPS (2003) Human casualties and livestock depredation by black and brown bears in the Indian Himalaya, 1989-98. Ursus 84-87

12. Dai Y, Hacker CE, Zhang Y, Li W, Zhang Y, Liu H, Zhang J, Ji Y, Xue Y, Li D (2019) Identifying the risk regions of house break-ins caused by Tibetan brown bears (Ursus arctos pruinosus) in the Sanjiangyuan region, China. Ecol Evol 1-12. https:// doi.org/10.1002/ece3.5835

13. Dar NI, Minhas RA, Zaman Q, Linkie M (2009) Predicting the patterns, perceptions and causes of human-carnivore conflict in and around Machiara National Park, Pakistan. Biol Conserv 142(10):2076-2082

14. Hashimoto Y (2002) Seasonal food habits of the Asiatic black bear (Ursus thibetanus) in the Chichibu Mountains, Japan. Mammal Study 27(1):65-72

15. Hwang MH, Garshelis DL (2007) Activity patterns of Asiatic black bears (Ursus thibetanus) in the central mountains of Taiwan. J Zool 271:203-209

16. Hwang MH, Garshelis DL, Wu YH, Wang Y (2010) Home ranges of Asiatic black bears in the Central Mountains of Taiwan: gauging whether a reserve is big enough. Ursus 21(1):81-96

17. Ikeda T, Uchida K, Matsuura Y, Takahashi H, Yoshida T, Kaji K, Koizumi I (2016) Seasonal and diel activity patterns of eight sympatric mammals in northern Japan revealed by an intensive cameratrap 
survey. PLoS ONE 11(10):1-16

18. Jamtsho Y, Wangchuk S (2016) Assessing patterns of human-Asiatic black bear interaction in and around Wangchuck Centennial National Park, Bhutan. Glob Ecol Conserv 8:183-189

19. Kabir M, Ghoddousi A, Awan MS, Awan MN (2013) Assessment of human-leopard conflict in Machiara National Park, Azad Jammu and Kashmir, Pakistan. Eur J Wildl Res 60(2):291-296

20. Kabir M, Hameed S, Ali H, Bosso L, Din JU, Bischof R, Redpath S, Nawaz MA (2017) Habitat suitability and movement corridors of grey wolf (Canis lupus) in Northern Pakistan. PLoS ONE 12(11):1-17. https://doi.org/10.1371/journal.pone.0187027

21. Kazmi S, Minhas RA, Ahmad B, Awan MS, Abbasi S, Ali U, Shakeel U, Dar NI (2019) Crop raiding by Himalayan black bear: a major cause of human-bear conflict in Machiara National Park, Pakistan. J Anim Plant Sci 29(3):854-863

22. Leuchtenberger C, de Oliveira ES, Cariolatto LP, Kasper CB (2018) Activity pattern of medium and large sized mammals and density estimates of Cuniculus paca (Rodentia: Cuniculidae) in the Brazilian Pampa. Braz J Biol 78(4):697-705. https://doi.org/10. 1590/1519-6984.174403

23. Lewis JS, Rachlow JL (2011) Activity patterns of black bears in relation to sex, season, and daily movement rates. West N Am Nat 71(3):388-396

24. Liu F, McShea W, Garshelis D, Zhu X, Wang D, Gong JE, Chen Y (2009) Spatial distribution as a measure of conservation needs: An example with Asiatic black bears in south-western China. Divers Distrib 15(4):649-659

25. McPherson JM, Sammy J, Sheppard DJ, Mason JJ, Brichieri-Colombi TA, Moehrenschlager A (2016) Integrating traditional knowledge when it appears to conflict with conservation: Iessons from the discovery and protection of sitatunga in Ghana.Ecol Soc21(1)

26. Minhas RA, Ahmed KB, Awan MS, Dar NI (2010) Habitat Utilization and Feeding Biology of Himalayan Grey Langur (Semnopithecus entellus ajex) in Machiara National Park, Azad Kashmir, Pakistan. Zool Res 2:177-188

27. Minhas RA, Khawaja BA, Awan MS, Zaman Q, Dar NI, Hassan A (2012) Distribution Patterns and Population Status of the Himalayan Grey Langur (Semnopithecus ajax) in Machiara National Park, Azad Jammu and Kashmir, Pakistan.Pak J Zool44(3)

28. Panthi S, Aryal A, Coogan SC (2019) Diet and macronutrient niche of Asiatic black bear (Ursus thibetanus) in two regions of Nepal during summer and autumn. Ecol Evol 9(7):3717-3727

29. Penteriani V, Zarzo-Arias A, Novo-Fernández A, Bombieri G, López-Sánchez CA (2019) Responses of an endangered brown bear population to climate change based on predictable food resource and shelter alterations. Glob Chang Biol 25(3):1133-1151

30. Qasim M, Hubacek K, Termansen M, Fleskens L (2013) Modelling land use change across elevation gradients in district Swat, Pakistan. Reg Environ Change 13(3):567-581

31. Raijman NL, Shenkar N (2016) From tropical to sub-tropical: prolonged reproductive activity of the invasive ascidian Microcosmus exasperatus in the eastern Mediterranean. Front Ecol Environ 4:102. https://doi.org/10.3389/fevo.2016.00102 
32. Reid D, Jiang M, Teng Q, Qin Z, Hu J (1991) Ecology of the Asiatic black bear (Ursus thibetanus) in Sichuan, China. Mammalia 55(2):221-238

33. Sathyakumar S, Sharma L, Charoo S (2013) Ecology of Asiatic black bear in Dachigam National Park, Kashmir, India Final project report. Wildlife Institute of India, Dehradun, pp 1-169

34. Songer M, Delion M, Biggs A, Huang Q (2012) Modeling impacts of climate change on giant panda habitat. Int J Ecol 1-12. doi:10.1155/2012/108752

35. Steinmetz R, Garshelis DL, Chutipong W, Seuaturien N (2013) Foraging ecology and coexistence of Asiatic black bears and sun bears in a seasonal tropical forest in Southeast Asia. J Mammal 94(1):1-18. https://doi.org/10.1644/11-MAMM-A-351.1

36. Sunar D, Chakraborty R, Sharma BK, Ghose PS, Bhutia P, Pradhan S (2012) Status and distribution of Asiatic Black Bear and the status of human-bear conflict at Senchal Wildlife Sanctuary. Technical Report (unpublished). WWF-India and West Bengal Forest Department, Kolkata, India, pp. 45

37. Tang X, Tang S, Li X, Menghe D, Bao W, Xiang C, Gao F, Bao W (2019) A Study of Population Size and Activity Patterns and Their Relationship to the Prey Species of the Eurasian Lynx Using a Camera Trapping Approach. Animals 9(11):1-12

38. Trent JA (2010) Ecology, habitat use, and conservation of Asiatic black bears in the Min Mountains of Sichuan province, China (Doctoral dissertation, Virginia Tech), pp. 1-102

39. Trolliet F, Vermeulen C, Huynen M-C, Hambuckers A (2014) Use of camera traps for wildlife studies. A review. Biotechnol Agron Soc Environ 18:446-454

40. Waseem M, Mahmood T, Hussain A, Hamid A, Akrim F, Andleeb S, Fatima H (2020) Ecology and Human Conflict of Asiatic black bear (Ursus thibetanus laniger) in Mansehra District, Pakistan. Pak J Zool 52(4):1443-1451. DOI: https://dx.doi.org/10.17582/journal.pjz/20180209100205

41. Yamamoto T, Tamatani H, Tanaka J, Yokoyama S, Kamiike K, Koyama M, Seki K, Kakefuda S, Kato Y, Izawa N (2012) Annual and seasonal home range characteristics of female Asiatic black bears in Karuizawa, Nagano Prefecture, Japan. Ursus 218-225

42. Zahoor B, Ahmad B, Minhas RA, Awan MS (2021c) Damages done by black bear (Ursus thibetanus) in Moji Game Reserve and its surroundings, Leepa Valley, Azad Jammu and Kashmir (Pakistan). Pak J Zool 53(1):1-9. doi: https://dx.doi.org/10.17582/journal.pjz/20170317130336

43. Zahoor B, Liu X, Ahmad B, Kumar L, Songer M (2021d) Impact of climate change on Asiatic black bear (Ursus thibetnaus) and its autumn diet in the northern highlands of Pakistan. Glob Chang Biol. DOl:10.1111/gcb.15743

44. Zahoor B, Liu X, Kumar L, Dai Y, Tripathy BR, Songer M (2021b) Projected shifts in the distribution range of Asiatic black bear (Ursus thibetanus) in the Hindu Kush Himalaya due to climate change. Ecol Inform 63:101312. https://doi.org/10.1016/j.ecoinf.2021.101312

45. Zahoor B, Liu X, Wu P, Sun W, Jia X, Lv Z, Zhao X, He X, He B, Cai Q, Songer M (2021a) Activity pattern study of Asiatic black bear (Ursus thibetanus) in the Qinling Mountains, China, by using infrared camera traps. Environ Sci Pollut Res 1-8. https://doi.org/10.1007/s11356-020-12325-3 
46. Zeller KA, Nijhawan S, Salom-Pérez R, Potosme SH, Hines JE (2011) Integrating occupancy modeling and interview data for corridor identification: a case study for jaguars in Nicaragua. Biol Conserv 144(2):892-901

47. Zhang J, Hull V, Huang J, Zhou S, Xu W, Yang H, McConnell WJ, Li R, Liu D, Huang Y, Ouyang Z (2015) Activity patterns of the giant panda (Ailuropoda melanoleuca). J Mammal 96(6):1116-1127

48. Zhang Y, Liu X, Lv Z, Zhao X, Yang X, Jia X, Sun W, He X, He B, Cai Q, Zhu Y (2019) Animal diversity responding to different forest restoration schemes in the Qinling Mountains, China. Ecol Eng $136: 23-29$

\section{Figures}

\section{Figure 1}

Map showing camera sites, interview sites and boundary of the study area (Machiara National Park, AJ\&K, Pakistan) 


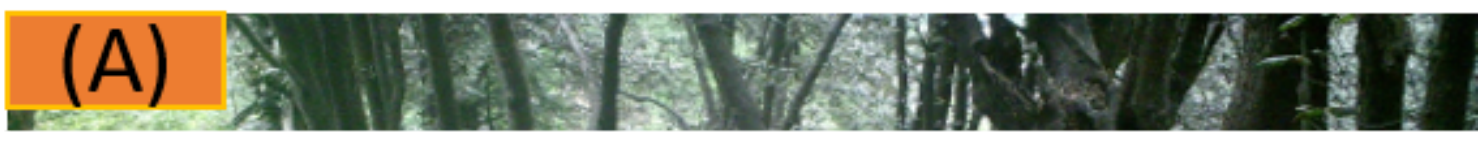

Figure 2

Asiatic black bear captured by infrared camera traps (a) inside and (b) outside the forests of Machiara National Park (MNP), AJ\&K, Pakistan. Dated: 08-07-2020 
(a)

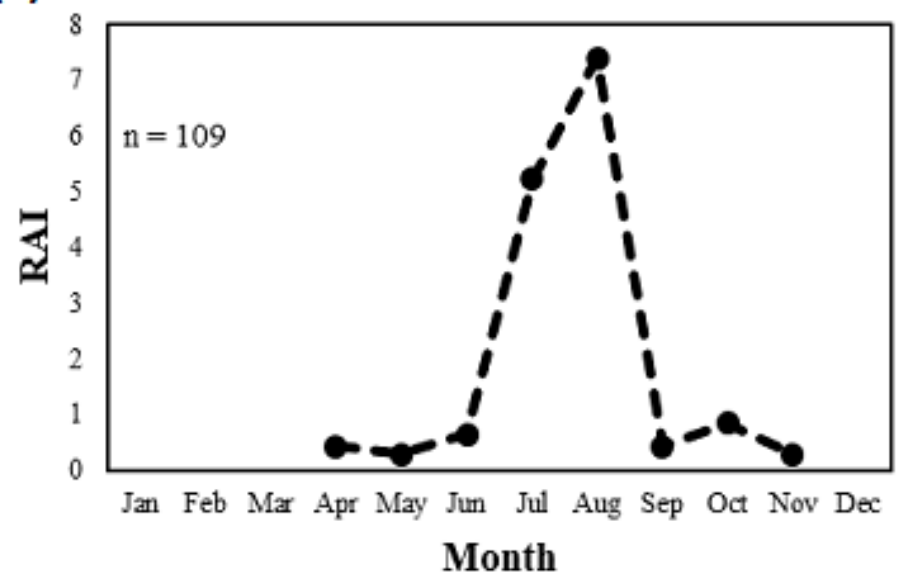

(b)

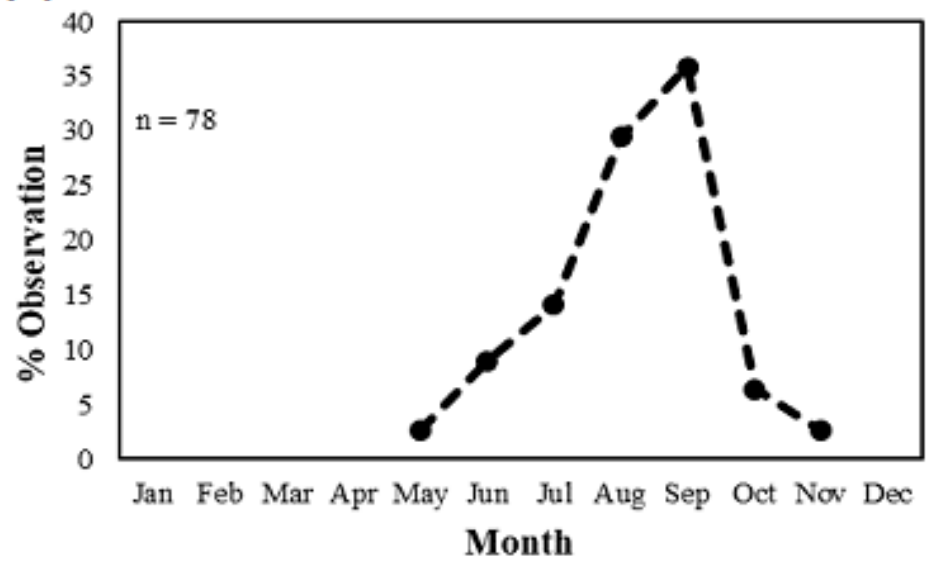

Figure 3

Monthly activity pattern of black bears based on (a) camera traps and (b) human observations in Machiara National Park, AJ\&K, Pakistan
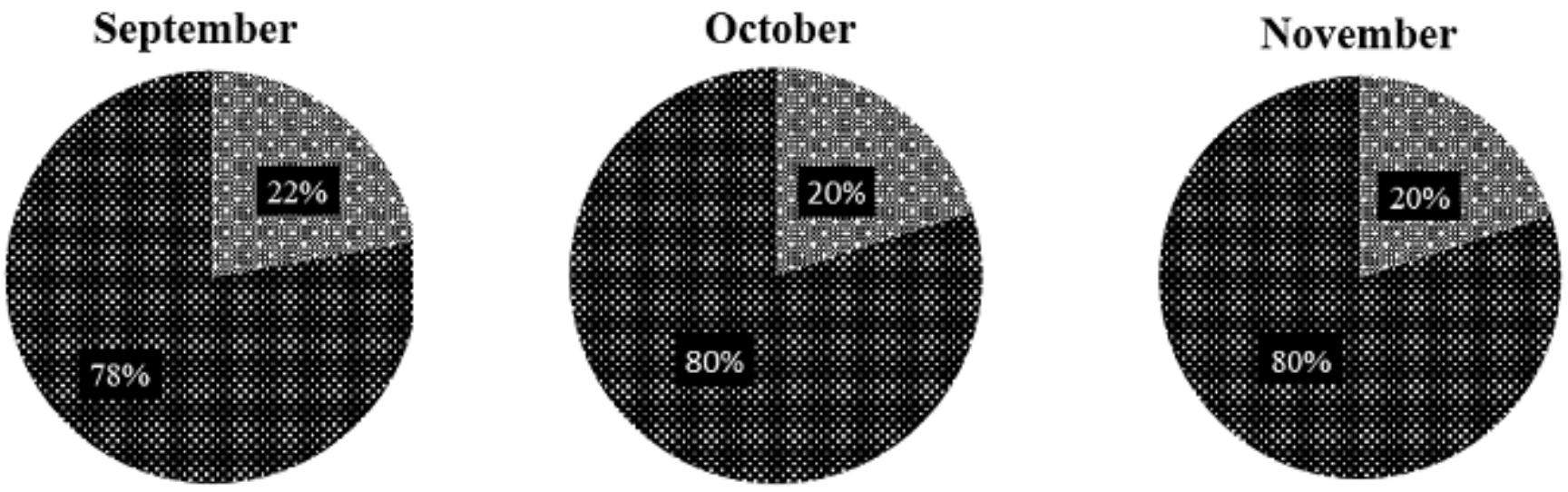

偻

\section{Figure 4}

Indigenous knowledge about intensity of black bears activity inside and outside the forests of Machiara National Park during autumn season 


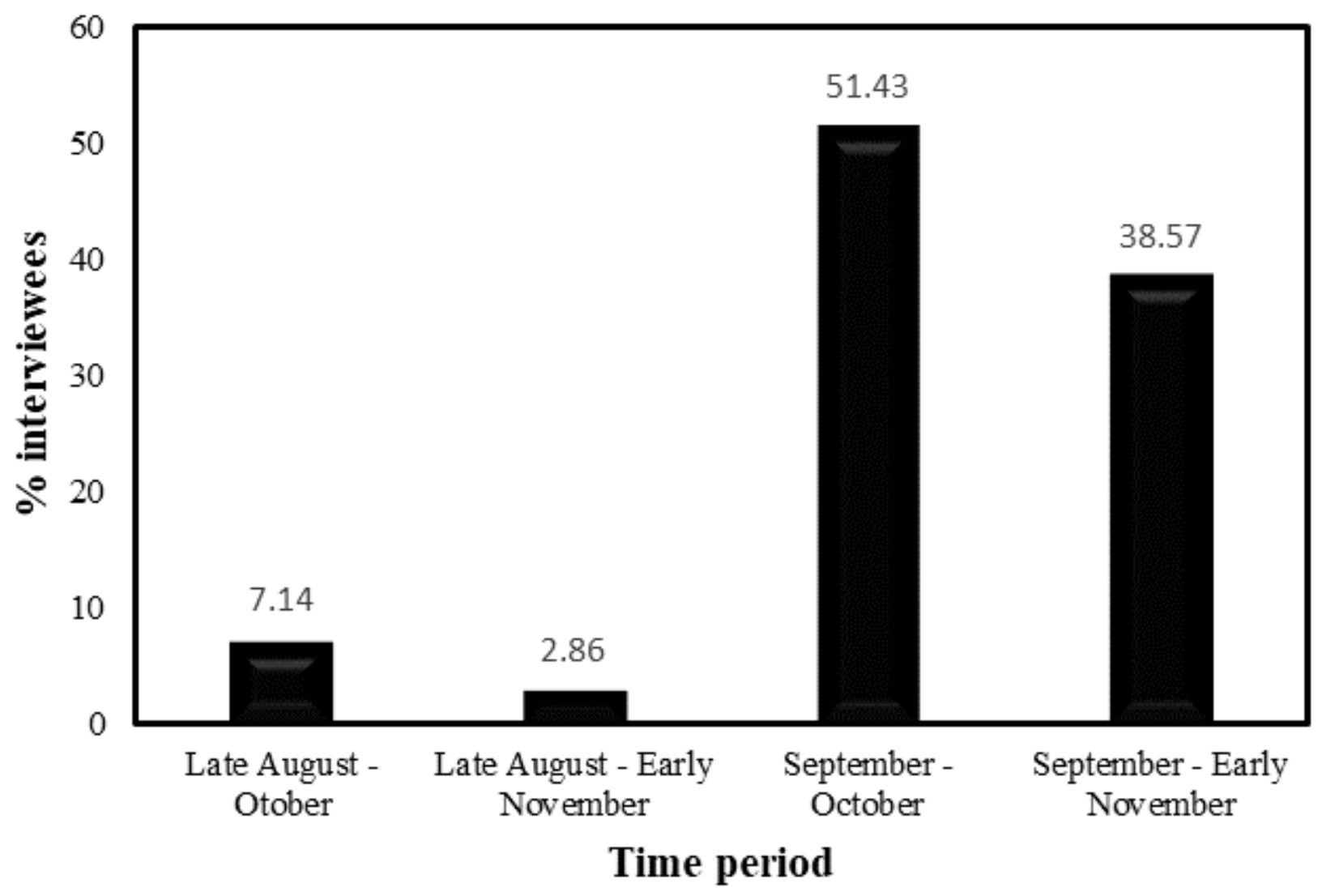

Figure 5

Pattern of crop raiding by black bears around Machiara National Park, AJ\&K, Pakistan

\section{Supplementary Files}

This is a list of supplementary files associated with this preprint. Click to download.

- Sepplementary1.docx 